\title{
CONCEPT OF THE NEW SYSTEM FOR THE MANDIBLE BASE FRACTURE FIXATION
}

\author{
Dominik Pachnicz ${ }^{1}$, Agnieszka Szust ${ }^{1}$ \\ ${ }^{1}$ Wroclaw University of Technology, Faculty of Mechanical Engineering, Wybrzeże Wyspiańskiego St. 27, 50-370 \\ Wrocław, Poland. E-mail: agnieszka.szust@pwr.edu.pl
}

\section{Introduction}

Mandible fractures are one of the most frequently occurring craniofacial trauma. Despite the fact that fixation techniques available nowadays give satisfying results, there is still need to search for new solutions. Complications and technical considerations related to those methods are still encountered. The aim of this article is to present concept of a fixation system for the mandible base fractures. Design of the system is modular, it consists of layered, $0,5 \mathrm{~mm}$ thick titanium mesh. Compared with commonly used miniplates, smaller thickness of components allows for greater adaptation to mandible bone geometry. The system can be adapted to all-embracing applications in cases of simple and comminuted fractures.

\section{Methods}

\subsection{Models production and analysis details}

The numerical mandible model was created on the base of polyurethane Synbone 8596 model of the mandible. Two volumes corresponding to materials of cortical and cancellous bone were generated. The cortical bone volume was obtained from laser scanning, cancellous was based on computer tomography results. Isotropic elastic properties - Young's Modulus and Poisson's Ratio were assigned to components. Finite element method (FEM) in Ansys 15.0 was utilized to solve number of boundary problems. Contact between mesh layers, bone- implant and between bone fragments were considered to be frictional. Strain intensity in the bone material, as well as von Mises stress values in designed elements are the index of the system effectiveness [1, 2]. Proposed fixation was also compared with recommended by AO Foundation techniques: double miniplate for simple and reconstruction plate for comminuted fracture case [3]. Additionally analysis of full, intact mandible was performed.

\subsection{Simulation of mastication}

The values of muscle forces were estimated to generate reaction force on the incisors circa $60 \mathrm{~N}$, which is an average value of occlusal force 6 weeks after the operation. [4]. In the numerical calculation boundary conditions considered muscle forces and their directions. On the place of condylar process head zero displacement in all directions was assumed. Upward translation of incisors was fixed. Muscles were modeled as forces applied in the insertion places. Three elevator muscles of the mandible: masseter, temporalis and medial pterygoid were taken into consideration in the calculation. The scheme showing boundary condition and mandible loading is presented on Fig. 1.

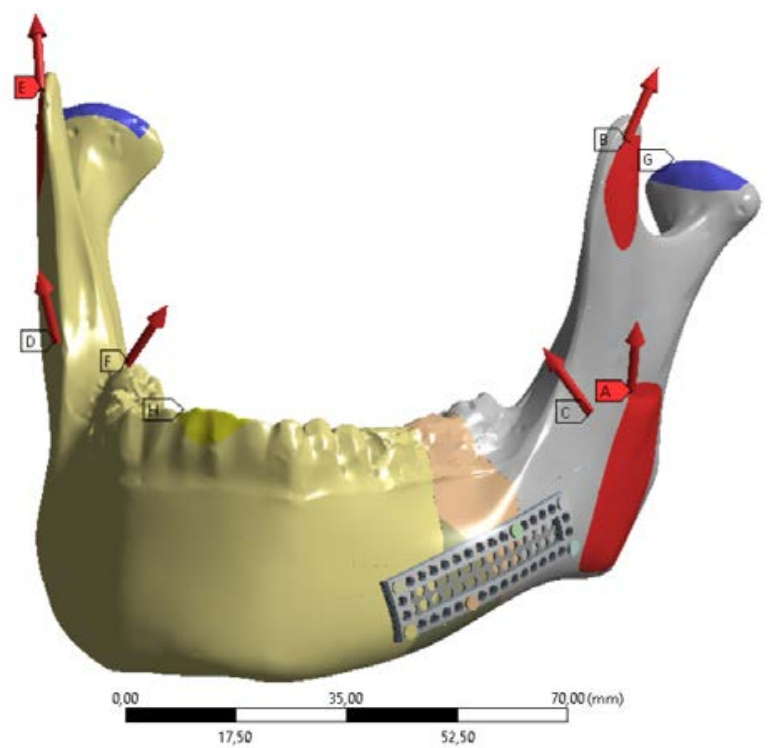

Fig. 1. Boundary conditions applied in mastication simulation:G-fixed support, A,D- masseter, C,F-medial pterygoid, B,E- temporalis, H- upward fixed 


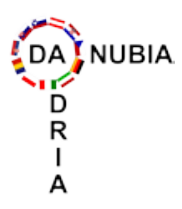

\section{Results}

The results show that the new construction is able to fulfill strength and stability requirements for carrying average occlusal forces occurring in mastication process during first few weeks after surgical procedure. The conditions in bone exhibit noticeable resemblance to standard implants and new system application. Exemplary comparison of simulation for comminuted case with use of new system and standard reconstruction plate is presented on the Fig. 2. The results of numerical analysis are presented in the Tab. 1. In all cases strain intensity in cortical bone did not exceeded threshold value above which microfractures and bone resorption is remarkable. Appearing in implant loads are under materials yield point.

a)

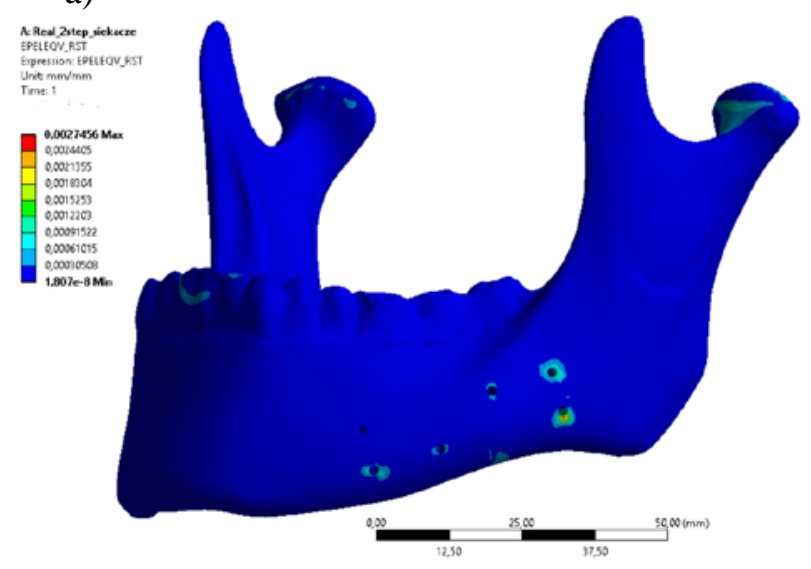

b)

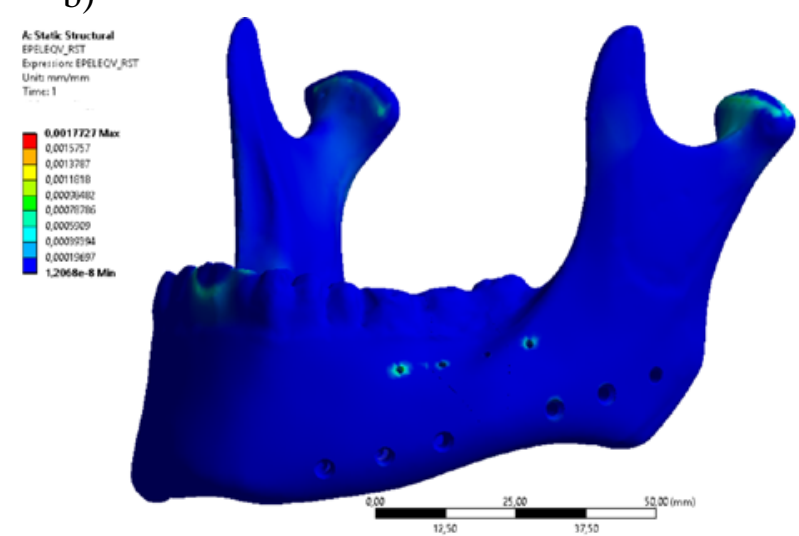

Fig. 2. Comparison of strain intensity in cortical bone: a) conceptional system, b) standard method with reconstruction plate

\begin{tabular}{|c|c|c|}
\hline $\begin{array}{c}\text { Type of } \\
\text { fixation and } \\
\text { fracture type }\end{array}$ & $\begin{array}{c}\text { Equivalent } \\
\text { Elastic Strain } \\
\text { [mm/mm] }\end{array}$ & $\begin{array}{c}\text { Equivalent } \\
\text { (von-Mises) Stress } \\
\text { [MPa] }\end{array}$ \\
\hline $\begin{array}{c}\text { Standard } \\
\text { simple }\end{array}$ & 0,0011 & 85,15 \\
\hline $\begin{array}{c}\text { Conceptional } \\
\text { simple }\end{array}$ & 0,0011 & 122,82 \\
\hline $\begin{array}{c}\text { Standard } \\
\text { comminuted }\end{array}$ & 0,0018 & 187,52 \\
\hline $\begin{array}{c}\text { Conceptional } \\
\text { comminuted }\end{array}$ & 0,0027 & 192,17 \\
\hline
\end{tabular}

Tab. 1. Results of numerical analysis

\section{Remarks}

- This preliminary research constitutes the foundation for the further extended laboratory and numerical tests

- Obtained results suggest that proposed conceptional solution fulfills strength and deformation requirements for the element as well as stability condition for the bone

\section{References}

[1] Knoll W.D., Gaida A., Maurer P. Analysis of mechanical stress in reconstruction plates for bridging mandibular angle defects, J. Craniomaxillofac. Surg., 2006, Vol. 34(4), 201209.

[2] Chladek W., Żmudzki J., Lipski T. Finite element analysis of mandible equilibrium depending on the way of its loading and supporting, Acta of Bioengineering and Biomechanics, 200, Vol. 2(1), 63-69.

[3] https://www2.aofoundation.org (18.05.2017)

[4] Tate G, Ellis E III, Throckmorton GS (1994) Bite forces in patients treated for mandibular angle fractures. J Oral Maxillofac Surg 52:734-736 